\title{
Mind the gap
}

\author{
L. D'Cruz'
}

\section{Key points}

Explains the difference between claims-made and occurrence-based indemnity.
Describes the difference between discretionary cover and contractual cover when choosing professional indemnity.
Sets out what the GDC requires registrants to have with regards to professional indemnity.

This article looks at the provision of professional indemnity in the UK, what the different products are and the importance of making choices appropriate to your needs to fulfil the statutory and ethical obligation to have appropriate indemnity as a registered dentist.

What is the difference between occurrencebased indemnity (regarded as the gold standard) and claims-made indemnity - and does it matter? The difference is important and choosing the wrong option can leave a practitioner potentially seriously out of pocket. Reading the small print may be tedious but in the case of indemnity it can be crucial.

\section{How often do you actually bother to read the fine print?}

When your mobile phone requires you to click 'I accept' when an upgrade is required? When you buy a train ticket online or sign the car hire rental agreement at the airport? When there is a knock on the door, someone hands you a parcel and thrusts a signature pad in front of you inviting your illegible mark on it using a spindly little twig-like object? There are many terms and conditions which only become relevant if something does not go according to plan and since none of us ever imagine that 'something' is going to happen to us, well, we just sign the documents and carry on with our busy lives.

At the airport car rental office you might have considered, briefly, the value of the excess

'General Dental Practitioner, Woodford Green, Essex Correspondence to: Len D'Cruz

Email: lendcruz1@gmail.com

Refereed Paper. Accepted 24 October 2018

DOI: 10.1038/sj.bdj.2018.1022 and debated whether you would be prepared to pay the first $£ 500$ of any damage sustained as you took the car off road or through the highly dodgy suburbs of a dangerous city. But that's probably about it.

I consider myself reasonably aware of the law and au fait with contracts but even I lose the will to plough on after the first half dozen paragraphs written in dense legalese prose. The mundane truth is that all you want in reality is the product and the benefits it gives you. The features of the product are of secondary importance. There is an instinctive, not always misplaced trust in the rubric on the page. Better and brighter people than I must have surely checked this for loopholes, making my attempts to seek them out redundant.

So what is it really that you want from your professional indemnity insurance? Basically, peace of mind from a trustworthy provider who understands a little bit about dentistry. But that's probably about it. Well okay, price does come into it, but as a sophisticated purchaser you know it's about quality and service as well as value. It is the reason you shop in particular supermarkets or purchase particular holidays and products.

However, there is a little more to the indemnity product you currently have whose certificate you will need to keep handy if the GDC ever come knocking. Following consultation with the profession, the GDC (Indemnity Arrangements) (Dentists and Dental Care
Professionals) Rules 2015 came into force in July 2015. This made it a legal requirement for all dentists and DCPs to have 'an indemnity arrangement in force that will provide appropriate cover' for your patients, in the event that harm befalls them as a result of your care or lack of care. It has always been an ethical requirement. ${ }^{1}$ Furthermore, from November 2015 the GDC also required registrants to make a declaration that they had relevant indemnity arrangements in place when renewing their GDC registration each year.

In that sense it's not actually about you but a patient protection matter. If your patients need remedial treatment or compensation for injuries or loss of income, there needs to be a system that allows them to access it without you having to fund it yourself or not fund it because you cannot afford it. But what exactly does the certificate on your wall provide you with when you need to make that call. What are you entitled to?

There are three things you would need to look for in any dental indemnity or insurance product:

1. Is it a contractual insurance policy or discretionary cover?

2. Is it occurrence based or claims made?

3. Do you get comprehensive advice, risk management education and timely support from a dentally qualified team as well as from lawyers who understand the practice of dentistry and a proven track record of helping and supporting dentists? 
The GDC are not concerned with what you have and do not dictate what kind of cover you choose. As long as your indemnity or insurance would enable a patient to claim compensation if this were ever necessary, it is up to you to decide which type of cover would be the most appropriate to suit your needs. ${ }^{2}$

\section{Contractual insurance versus discretionary cover}

An insurance policy operates on the same basis as your house, car and travel insurance. Your claim will be covered if it falls within the wording of the contract. The policy wording is therefore quite important since it defines what is covered as much as what is not covered by this legally enforceable agreement. If the company declines to cover you under this contractual insurance agreement, the final arbiter would be the Financial Ombudsman Service, which is a statutory body that will independently look into any complaints you have.

That same 'certainty' and legal protection does not exist with discretionary cover, often provided by the traditional mutual indemnity organisations. In these cases, as a member of that mutual company, paying their annual subscriptions, you have a right to seek advice, support and legal assistance. The difference is the organisation can exercise its absolute discretion not to assist you even if you are entitled to seek it because you are in the right subscription category and have paid the correct fees and the matter is within the scope of cover.

Those companies that operate on the basis of discretionary cover will point to their long histories of indemnifying dentists and argue that no patient has ever been left uncompensated as result of discretion being used to decline a member who was properly entitled to seek assistance. In some cases this is true but in others it is a matter of public record that it is not always true. They argue that in cases where there are wider important issues at stake they will exercise their discretion to assist a member for the benefit of the profession at large when contractual insurance may not have covered it. There is, however, no Financial Ombudsman Service to adjudicate whether or not your claim should be covered under the discretionary policy as there is with contractual insurance. The directors of these mutual companies are empowered with absolute discretion when determining when and to what extent it will assist members and grant indemnity. It is argued that since the fund is a mutual fund, a refusal to assist an individual member can been justified on the basis that it would not be in the interests of other members to incur the costs of assisting in some cases.

The flip side of the certainty of contractual insurance may be the lack of discretion in dealing flexibly with any claims or novel situations at the fringes or beyond the scope of the policy that a discretionary approach might encompass. But the reality is that nobody knows for sure whether or not contractual insurance policies have given the insured dentist the benefit of the doubt in individual cases and if so, how often.

\section{Occurrence based or claims made?}

All policies have a start and end date - when you first take out the policy and when you stop working, retire, change indemnity companies, take an extended break for sickness, travel or parental leave, stop paying the subscription fees or when you die

With occurrence-based cover, as long as you are paying the right subscription rate at the time the incident occurred that later gave rise to a claim, you will be covered. This means that if you did something negligent but retired the next day and stopped your payments, even if the complaint and legal claim is made against you, say three years later, you will be covered under an occurrence-based policy. Under this occurrence-based policy, the dentist pays that single subscription each year he/she practices and makes complete provision for his/her professional risk and protection for patients in perpetuity.

Claims made is different. In the case above, if you do something negligent and then retire the next day, you will need to have 'run off' arrangements in place to cover you for any claims that are made after you stop paying the main policy premiums. These run off arrangements are sometimes built into the policy, but in other cases require additional payments to be made or may not be offered to you at all.

The gold standard for dentists and other medical healthcare professionals is occurrence based. This is because it is quite common for complaints and allegations of negligence to arise a long time after the treatment complained of was provided. When looking at these figures, only about a quarter of the potential adverse incidents in a year will have given rise to a claim against the dentist within the first 12 months of the treatment being provided. A further quarter of the total claims that will eventually land on the doormat of the dentist's surgery will be made in months 13-24 following the date of treatment, with the remainder $50 \%$ tailing off gradually over the next few years.

In some cases it could be many years before the patient discovers that negligent treatment may have been carried out on them and they would be entitled to make a civil claim for compensation. Even five or six years later, 5-10\% of the total number of claims for that original year will not have been made. These later ones may be the more complex and expensive to defend or settle.

With a claims-made policy you might need to continue paying a premium to the company long after you stopped working to ensure you would still be covered. Even when some run off is built into a claims-made policy, there is often a limit placed on how long this continues - in which case you are on your own for any claims after that and in effect you are in breach of the GDC's indemnity requirements. This is the gap you will need to bear in mind when you end a claims-made policy. So this means that if you leave this claims-made policy after a year you will need to cover for this 'tail' of potential claims which could cost as much or more than the first year's premium. In some policies this might mean a low year one premium but the second year premium increases to cover the year one claims that get reported in Year 2, as well as the claims that will arise and be made in Year 2 of the claims-made policy.

Interestingly, there is no legal obligation to offer or sell the 'run off' cover to any dentist who leaves or joins another company. Ironically, it is at their discretion to do so; one more thing to think about if you decide to end a claims-made policy.

It can sound attractive to have this 'run off' cover built into the premiums you pay from the very start of your policy but you will still need to know for how long that run off cover lasts. You don't need to ask this question at all if you have an occurrence-based policy with an insurance company or a mutual organisation.

It is important to note that mutual indemnity companies (for example, Dental Protection Limited, Dental Defence Union and Medical and Dental Union Scotland Defence) can provide both claims-made and occurrencebased products, as well as discretionary and insurance products, although they would need to meet onerous additional regulatory requirements before the latter becomes possible. Likewise the insurance companies in 
the dental market provide a combination of different products. Knowing and recognising the terminology helps in a sometimes very confusing market.

\section{Dentist for dentists}

Relationships really do matter and working with an indemnity provider who understands how you practice, the stresses and challenges you face, the complexity of the clinical care you provide and the environment in which it is delivered is the first step to having an empathetic and supportive relationship. Most of the companies in the current indemnity market do try to deliver a dentist focussed solution, but do it in different ways with varying degrees of success. Some are definitely better than others. There will also be issues, such as business matters that impinge on the clinical and legal aspects of an enquiry or case which the indemnity organisations may not cover themselves.

Indemnity and your choice of bank are most probably decisions you make early on in your career, probably as dental students. Most readers are probably still with that same bank but this market has opened up dramatically with different providers taking on the traditional bricks and mortar high street lenders, offering newer products at competitive prices. Increasingly dentists are reconsidering the choice they made about their indemnity provider now based in part on cost, but also on other quality and value issues.

Before you move make sure you read the fine print and mind those gaps because the wrong decision can have a huge impact on your career and ability to practise.

1. GDC. Standards for the dental team. General Dental Council. 2013. Available at https://www.gdc-uk.org/api/ files/NEW\%20Standards $\% 20$ for $\% 20$ the $\% 20$ Dental\%20 Team.pdf (accessed October 2018).

2. GDC. Guidance on indemnity. General Dental Council. 2017. Available at https://www.gdc-uk.org/professionals/standards/indemnity (accessed October 2018). 